\title{
Pakistan's Community-based Lady Health Workers (LHWs): Change Agents for Child Health?
}

\author{
Shehla Zaidi, Ph.D. ${ }^{1}$, Maryam Huda, $\mathrm{MSc}^{1}$, Ammarah Ali, $\mathrm{MSc}^{1}$, Xaher Gul, MPH ${ }^{1}$, \\ Rawshan Jabeen, $\mathrm{MSc}^{1}$ \& Mashal Murad Shah ${ }^{1}$ \\ ${ }^{1}$ Department of Community Health Sciences, Aga Khan University, Karachi, Pakistan \\ Correspondence: Shehla Zaidi, Department of Community Health Sciences, Aga Khan University, National \\ Stadium road, Karachi, Pakistan. E-mail: Shehla.zaidi@aku.edu
}

Received: February 10, 2020 Accepted: June 10, 2020 Online Published: September 29, 2020

doi:10.5539/gjhs.v12n11p177 URL: https://doi.org/10.5539/gjhs.v12n11p177

\begin{abstract}
Background: In Pakistan's high child mortality context, a large-scale Lady Health Worker (LHW) Program raises the need to look at whether LHWs are delivering their key mandate as agents of change for child health. This study examines the quantity and quality of LHW interactions with mothers for child health and their impact on mothers' knowledge and child health practices.
\end{abstract}

Methods: 1,968 mothers of children $<2$ years $(n=1,968)$ were interviewed through a cross-sectional survey in two rural districts of Pakistan focusing on immunization, nutrition, and early child illness. Data on frequency of LHW's visits; services provided, specific services related to routine immunization (RI), nutrition and child illness, and maternal knowledge and practices were analyzed using median values for continuous variables and counts and percentages for categorical data.

Results: Monthly visits by LHW were reported by only $63 \%$ of LHW covered households. During LHW monthly encounters, Oral Polio drops administration was most frequently reported (77\%), followed by RI (59\%), breastfeeding counseling (20\%), child illness management advice (18\%), growth monitoring $(9.5 \%)$, while none reported receiving hygiene counseling. Although LHWs were reported to be the main information source for child health; limited impact of LHW-mother interaction was seen on maternal knowledge and practices: $76 \%$ mothers reported receiving ORS packets from LHWs but only $27 \%$ knew of correct usage, only $34 \%$ washed hands before feeding children, less than a third could correctly recall early signs of pneumonia and awareness of Vaccine Preventable Diseases other than Polio ranged from $42 \%-9 \%$ only.

Conclusion: Although LHWs are main information source for child health services but infrequent, poor quality household encounters indicate ineffective delivery on the key mandate of community-based child health. Policy debate instead of focusing on scaling up or downsizing the program, should prioritize quality and supervision to improve value for money of a critical community resource.

Keywords: child health, community health workers, Pakistan, performance

\section{Introduction}

In several Low Middle Income Countries (LMICs), community health workers (CHWs) are the first point of contact for the community to access health services. Their foremost purpose has been the provision of frontline advice, treatment and referral for childhood illness, under-nutrition, maternal care, malaria and HIV treatment (Gilmore \& McAuliffe, 2013; Brenner et al., 2011; Mambulu-Chikankheni, Eyles, \& Ditlopo, 2018; Uganda, 2016). In countries having weak health systems, long distances, underserved populations and patriarchal societies, the deployment of CHWs has been argued to reduce barriers to healthcare. Within the area of child health, the pivotal role of CHWs is for increasing community uptake of evidence based preventive and promotive practices to reduce child mortality as well as contribute to early recognition and referral so that childhood diseases can be dealt with timely at health facilities. While there is a spate of evidence on CHW programs contributing to improving community health outcomes (Hafeez et al., 2011), much of this comes from the controlled settings of randomized trials or discrete projects providing well-funded and supervised CHW interventions (Horwood et al., 2017; Memon et al., 2015). There is less conclusive evidence on impact of mainstream CHW programs.

Pakistan's Lady Health Worker (LHW) Programme, is one of the largest and longest standing CHW program in the 
world. Established in 1994 as a flagship program by the late Prime Minister Benazir Bhutto it has a workforce of more than 110,000 Lady Health Workers (LHWs) (Nina Zhu, 2014), covering approximately $50 \%$ of the population forming the backbone of Pakistan's primary care delivery at the village level and referrals back to government health facilities. National policy targets propose doubling of numbers with 1

$00 \%$ coverage in rural areas by 2025 (Management, 2009). Females with up to 8 years of schooling are recruited from targeted villages, trained and paid a monthly stipend starting from \$110 (PKR 17000-Basic Pay Scale-5) (Report, 2018) to deliver maternal, child health and family planning services in low income rural and peri-urban areas of Pakistan. Each LHW serves a 1000-1500 population or approximately 200 households. LHWs are provided with 15 months of training- 3 months classroom and 12 months field-based, field checks by Lady Health Supervisors of each cluster of 15-20 LHWs (Hafeez et al., 2011), monthly basic supplies, and undergo a week of reporting at the nearest government primary care clinic. The program requires LHW is to maintain records of all eligible households having a child less than 5 years age or a pregnant woman, conduction of monthly visits for preventive and promotive care, provision of community-based counseling sessions, timely referrals to health facilities and update of birth and death record.

In Pakistan's high child mortality context, where U5 years mortality rate of 75 per 1000 live births (National Institute of Population Studies (NIPS) 2019) is far behind the Sustainable Development Goal (SGD) target of 25 per 1000 live births, LHW based interventions can be critical in accelerating the reducing of $<5$ years mortality. Diarrhea and pneumonia remain one of the top preventable causes of deaths in under-five children in Pakistan (National Institute of Population Studies (NIPS) 2013; National Institute of Population Studies (NIPS) 2019), whereas lack of infant and young child feeding (IYCF), poor hygiene and incomplete immunizations are associated as key underlying drivers (Bhutta et al., 2008; Walker et al., 2013). LHWs monthly routine includes essential child health tasks of counseling on routine immunization, provision of intramuscular vaccines in certain provinces, early recognition and referral of childhood illnesses, growth monitoring, de-worming, counseling on breastfeeding and infant feeding, counseling on handwashing, hygiene and clean drinking water (Hafeez et al., 2011).

However, 25 years since the start of this program, questions are emerging whether to simply push on for extension of LHWs in remaining under-covered areas or look more critically at making this program more impactful. The last programme evaluation conducted more than a decade ago in 2009, documented improvements in LHW covered areas over non-covered areas, but highlighted gaps in monitoring and supervision putting the program at risk of poor quality of delivery (Management, 2009). Since then there have been major policy developments impacting the LHW program. LHWs had a special status in the initial years as community representatives paid a monthly stipend in recognition of their services. The 2012 Supreme Court order regularized LHWs as government workers providing them a regular salary but also de-linked them as community representatives accountable to the community (Iqbal, 2014). The devolution of health to the provinces, also devolved the LHW program amongst other vertically run preventive care programs, but did not match up with sufficient fiscal transfer, limiting policy ownership of the LHW program in the provinces (Zaidi et al., 2019). Furthermore, Pakistan's attempts on Polio eradication has pressed LHWs into increasing the number of house to house oral Polio drop campaigns, adding to the main job of primary care. Hence, it is pertinent to investigate whether LHWs can continue to deliver the primary care agenda for which they were recruited or is a major re-think needed to help them deliver better?

In this study, we report on the delivery of essential child health services by LHWs in a high child mortality context in Pakistan. Using a community-based household survey in 2 under-served districts of Pakistan we provide quantifiable information on what services are actually being delivered on the ground by LHWs and does their input get translation into maternal practices for child health. The study examines 2 areas: i) the quantity and quality of LHW interactions with mothers for child health at the household level; ii) maternal knowledge and childcare practices for childhood illnesses, preventive care practices (feeding practice, hygiene and routine immunization) in households covered by LHWs. We attempt to assess whether LHW is functioning as an agent of change for child health and to provide actionable recommendations on where the program delivery should be strengthened.

\section{Methodology}

\subsection{Study Design and Setting}

A descriptive cross-sectional study was undertaken comprising of household structured interviews of mothers of $<2$ years children residing in LHW covered areas in two underserved rural districts of Pakistan. A structured questionnaire was administered to mothers living in LHW served household for more than 6 months. Data was collected on frequency of LHW visits to household, child health services provided during LHW visits, mothers' recognition and handling of pneumonia and diarrhea, maternal knowledge and practices related to essential 
preventive services of routine immunization, infant feeding, and hygiene. The survey was conducted over September-November 2018 in Shaheed Benazirabad (SB) and Tando Muhammad Khan (TMK) districts located in the South and North regions of Sindh province. Both of the districts have predominantly rural population, $70 \%$ in SB and 79\% in TMK (Statistics 2018) with full routine immunization coverage of 36\% in SB and 32\% in TMK. The stunting (moderate to severe) prevalence is 55\% in SB and 59\% in TMK respectively (Sindh Bureau of Statistics 2015.).

\begin{tabular}{|l|l|}
\hline 6 union councils - Shaheed Benazirabad \\
\hline 100 sampling units - LHWs \\
\hline
\end{tabular}

Figure 1. Multi-stage cluster sampling to enroll 2000 households

\subsection{Sample Size}

The household sample size was calculated to be able to detect the reporting of a common child illness in children under two years of age. Diarrhea prevalence of $23 \%$ in $<2$ years children was used in the determination of sample size. A sample of 1718 eligible households was calculated based on $80 \%$ power and $5 \%$ level of significance to detect reporting of diarrhea, factoring in $90 \%$ response rate and a design effect of 1.5 over LHW versus non-LHW covered area.

\subsection{Sampling}

Districts are administratively divided into union councils comprising approximately of 10,000 populations. Multi-stage cluster sampling approach was used to enroll eligible households. In the first stage, 12 union councils served by LHWs were randomly selected across the 2 districts, comprising 6 union councils in each district. In the next stage, each of the sampled union council was broken down into sampling units of 1000 population served by LHWs and 200 sampling units, 200 units were randomly selected from the total listing. In the third stage, 10 eligible households were systematically sampled from each of the 200 units to achieve a sample size of 2000 households. An eligible household was one having at least one child of age less than 5 years and served by the LHW for at least 6 months. From the first eligible household, every fifth household was selected and until 10 eligible households were sampled from one cluster (Figure 1).

\subsection{Data Collection}

The interview tool was comprised of 4 sections: i) socio-demographic household information; ii) particulars of child $<2$ years of age including birth and child illness; iii) LHW's quantity and quality of visits; iv) maternal knowledge and practice of essential child health services prided by LHWs. Responses could be given in a combination of multiple choices and open-ended response formats. The tool was pretested in 5\% of the sample size prior to being finalized. Household interviews in the local language were carried out by 4 trained research assistants, supervised by a field supervisor and overseen by a field manager. The same team conducted interviews across both districts to maintain consistency. The completed questionnaires were daily verified by the field supervisor for completeness and errors, while $10 \%$ of the filled forms were randomly picked for checking by the field manager. All checked forms were sent to the central data management unit for double entry of data, using EpiData software version 3.1. Data was entered on a real-time basis and a statistician checked the quality of the entry and supervised data editing. Data set was analyzed using SPSS software version 19. The mothers' and LHW characteristics were described using median values and interquartile ranges (IQR) for continuous variables and 
counts and percentages for categorical data. Differences and proportions were tested using a chi-square test.

\subsection{Ethical Considerations}

Approval on study proposal, data collection and tool review was taken from the Ethical Review Committee (ERC) of Aga Khan University (AKU) (5413-CHS-ERC-18). Authorization to carry out the survey was obtained from the district health offices and deputy commissioners of SB and TMK respectively. Eligible mothers were invited to participate in the survey based on written informed consent and no monetary or other incentives were provided. A unique identification number was assigned to eligible participants at the time of recruitment to maintain anonymity during data entry, analysis and reporting.

\section{Results}

\subsection{Socio-Demographic Characteristics}

A total of 2004 females were interviewed comprising $95 \%$ of mothers and $5 \%$ of female caregivers when mother was unavailable. The profile of the households is typical of a rural, Pakistani population: $55 \%$ of the mothers were illiterate, $11 \%$ had completed primary school and 135 had completed high school. Occupation of father of U2 children was mainly daily wages: $56 \%$ worked on daily wages whereas $21 \%$ ran small business and remaining were in salaried jobs. Ethnic background of half of the participants was Sindhi: 53\% population spoke Sindhi as the first language, followed by $13 \%$ Seraiki, $11 \%$ Punjabi, $10 \%$ Urdu, $10 \%$ hindko/pashto.

\subsection{Services Delivered by LHWs During Visits}

All households (98\%) had been visited by LHW in the last 3 months, but only $63 \%$ reported regular monthly visits. The most frequently provided service was oral Polio drops administration reported by $77 \%$ of households (Table 1 ). Routine immunization were reported considerably less by $59 \%$ of households. Other child health services were even less commonly reported: Breastfeeding advice (20\%); child illness management (18\%), growth monitoring only $10 \%$, whereas hygiene counseling was not reported by any household. Participant mothers also asked about provision of maternal care services by LHW during visits: $40 \%$ mothers reported being counseled on ANC during last pregnancy; $30 \%$ reported PNC counseling by LHW and 37\% reported being advised on family planning.

Table 1. Services provided during LHW household visits

\begin{tabular}{lcc}
\hline Indicator & $\mathrm{n}=1968$ & Percent \\
\hline Percentage of households visited by LHWs once a month & 1241 & $63 \%$ \\
\hline Child health services provided by LHWs during HH visits & $\mathrm{n}=1968$ & Percent \\
\hline Polio drops only & 1525 & $77 \%$ \\
Breast feeding counseling & 392 & $20 \%$ \\
Child illness management & 363 & $18 \%$ \\
Growth monitoring & 194 & $10 \%$ \\
Hygiene Counseling & 1 & $0 \%$ \\
\hline Maternal care services provided by LHWs during HH visits & $\mathrm{n}=1968$ & Percent \\
\hline ANC checkup & 785 & $40 \%$ \\
Contraceptive methods & 720 & $37 \%$ \\
PNC checkup & 586 & $30 \%$ \\
\hline
\end{tabular}

\subsection{Routine Childhood Immunization}

Nearly two-third of the households $(67 \%)$ reported that LHWs as the source of information for routine childhood immunization whereas doctors $(16 \%)$, vaccinators $(12 \%)$, media $(2.6 \%)$ were minor sources and civil society organizations were hardly reported $(0.25 \%$ ) (Table 2$) .31 \%$ of mothers reported being counseled by LHWs during monthly home visits, whereas others obtained information from LHWs during visits to health house or sessions/ chance encounters.

For close to half of the households (59\%), the LHW was also the provider of routine childhood vaccinations while the remaining had children immunized by vaccinators or at health facilities. Most of the children (53\%) in the households that received childhood vaccinations from LHWs reported vaccinations being provided during 
monthly home visits.

Awareness on specific vaccine preventable diseases was highly variable with 59\% reporting awareness of Polio whereas awareness of other VPDs was much lower ranging between of $42 \%-9 \% .42 \%$ of mothers were aware of BCG, $31 \%$ of measles while Penta and Pneumococcal awareness was very low limited to $24 \%$ and $23 \%$ respectively. A sizeable number of respondents (26\%) were not aware of any VPD.

Table 2. Routine Childhood Immunization

\begin{tabular}{|c|c|c|}
\hline Source of information on routine immunization & $\mathrm{N}=1972$ & Percent \\
\hline LHW & 1321 & $67 \%$ \\
\hline Doctor & 306 & $16 \%$ \\
\hline Vaccinator & 227 & $12 \%$ \\
\hline Media & 53 & $3 \%$ \\
\hline Civil Society Organization CSO & 5 & $0.25 \%$ \\
\hline Provider of routine immunization & $\mathrm{N}=2004$ & Percent \\
\hline LHW (home/ LHW health house) & 1182 & $59 \%$ \\
\hline Vaccination at home & 781 & $39 \%$ \\
\hline Vaccination center & 642 & $32 \%$ \\
\hline \multicolumn{3}{|l|}{ RI service provided by LHW during HH visits } \\
\hline Provision of routine immunization vaccination during $\mathrm{HH}$ visit $(\mathrm{n}=3076)$ & 1637 & $53 \%$ \\
\hline Provision of counseling on Routine Immunization during HH visit ( $\mathrm{n}=1972$ ) & 620 & $31 \%$ \\
\hline Mothers Awareness of Childhood Immunizations & $\mathrm{n}=1972$ & Percent \\
\hline BCG & 826 & $42 \%$ \\
\hline Polio & 1156 & $59 \%$ \\
\hline Measles & 602 & $31 \%$ \\
\hline Don’t know & 515 & $26 \%$ \\
\hline Pentavalent & 481 & $24 \%$ \\
\hline Pneumococcal & 448 & $23 \%$ \\
\hline Rotavirus & 184 & $9 \%$ \\
\hline
\end{tabular}

\subsection{Nutrition}

Of the $9.5 \%$ children monitored for growth by LHWs during household visits, a third (35\%) are monitored for weight and only $17 \%$ for height (Table 3 ). Close to two-thirds of children monitored for growth $(68 \%)$ were referred by LHW to health facilities for further follow up.

Provision of advice on nutritional parameters was reported by only a third to a fifth of the mothers: $29 \%$ of mothers reported receiving weaning advice, $23 \%$ reported advice on nutritious food, and $20 \%$ reported breastfeeding advice. Only $17 \%$ of mothers had received counseling from LHWs on deworming and a mere $11 \%$ on development milestones.

Despite only a fifth of mothers having received weaning advice from LHWs at least half (51\%) reported exclusively breastfeeding for 6 months. Over $20 \%$ of mothers reported introduction of other fluids before 6 months of age, hence risking childhood infections and under-nutrition. Practices for weaning were more inadequate. Weaning was practiced at the appropriate age of 6 months in only $12 \%$ of children with most mothers delaying weaning to later months. 
Table 3. Nutrition

\begin{tabular}{|c|c|c|}
\hline Indicator & $\mathrm{n}=1968$ & Percent \\
\hline Growth monitoring provided by LHW during HH visit & 194 & $10 \%$ \\
\hline Growth monitoring practices used by LHWs (\%) & $\mathrm{n}=2004$ & Percent \\
\hline Weight & 696 & $35 \%$ \\
\hline Height & 343 & $17 \%$ \\
\hline Mid Upper Arm circumference & 53 & $3 \%$ \\
\hline Head circumference & 43 & $2 \%$ \\
\hline Others & 350 & $17 \%$ \\
\hline Referral of malnourished children by LHW ( $\mathrm{n}=2004)$ & 1363 & $68 \%$ \\
\hline Nutrition Counseling by LHWs during household visits & $\mathrm{N}=1972$ & Percent \\
\hline Weaning Advice & 569 & $29 \%$ \\
\hline Nutritious food & 430 & $23 \%$ \\
\hline Breastfeeding & 392 & $20 \%$ \\
\hline Deworming & 338 & $17 \%$ \\
\hline Development Milestones & 217 & $11 \%$ \\
\hline Exclusive breastfeeding practiced by mothers & $\mathrm{N}=1877$ & Percent \\
\hline $0-1$ months & 87 & $5 \%$ \\
\hline $2-3$ months & 121 & $6 \%$ \\
\hline $4-5$ months & 195 & $10 \%$ \\
\hline Till 6 months & 966 & $51 \%$ \\
\hline Did not breastfeed & 84 & $4 \%$ \\
\hline 7 and above & 418 & $22 \%$ \\
\hline Weaning initiation practiced by mothers & $\mathrm{n}=2004$ & Percent \\
\hline $0-1$ months & 33 & $2 \%$ \\
\hline $2-3$ months & 73 & $4 \%$ \\
\hline 4-5 months & 100 & $5 \%$ \\
\hline At 6 months & 244 & $12 \%$ \\
\hline Weaning after 6 months & 919 & $46 \%$ \\
\hline Don’t know & 184 & $9 \%$ \\
\hline
\end{tabular}

\subsection{Child Illness}

Child illness counseling and support was provided by LHWs in only $18 \%$ of monthly interactions with mothers. However, despite the infrequent advice, LHWs are the main provider of information on child illness detection and early management - $74 \%$ of households reported that LHWs is the source of information on recognizing and initial management of child illness, whereas doctors as source of information were reported by only $26 \%$ of households (Table 4). For the treatment of child illness, LHWs are a marginal source (3.5\%), with most households accessing private providers $(70 \%)$ and to lesser extent government facilities $(22 \%)$.

Mothers were questioned on diarrhea and pneumonia, the two largest cause's preventable deaths in children in Pakistan, as well as child care hygiene. Mothers did not recall being advised on hygiene for child care by LHWs during monthly interactions. Hygiene practices by mothers were poor with only $34 \%$ washing hands before feeding children, $48 \%$ reported use of boiled water for children and $32 \%$ covered food $\&$ water of children from flies \& dust.

Most households (76\%) reported receiving the Oral Rehydration Solution (ORS) provision from LHWs for use 
during childhood diarrhea. However only $27 \%$ of mothers had correct knowledge of ORS to be given after every loose motion during diarrhea. Less than a third of mothers could recognize key signs of pneumonia: $35 \%$ of mothers reported runny nose, $31 \%$ shortness of breath, $29 \%$ cough, $27.5 \%$ reported sounds in the chest, and only $14 \%$ mentioned increased respiratory rate.

Table 4. Early management of child illness

\begin{tabular}{|c|c|c|}
\hline Source for recognition of child illness & $\mathrm{n}=1459$ & Percent \\
\hline LHW & 1079 & $74 \%$ \\
\hline Doctor & 380 & $26 \%$ \\
\hline Source of treatment of child illness & $\mathrm{n}=827$ & Percent \\
\hline Private provider & 579 & $70 \%$ \\
\hline Government Centre & 184 & $22 \%$ \\
\hline LHW & 33 & $4 \%$ \\
\hline ORS provided by LHW during HH visits ( $\mathrm{n}=1930$ ) & 1465 & $76 \%$ \\
\hline ORS use during last childhood diarrheal episode by mothers & $\mathrm{n}=2004$ & Percent \\
\hline Once & 54 & 3 \\
\hline Twice & 211 & 11 \\
\hline Thrice & 978 & 49 \\
\hline After every stool & 541 & 27 \\
\hline Other & 185 & 9 \\
\hline Infant \& childcare hygiene practices by mothers & $\mathrm{n}=2004$ & Percent \\
\hline Hand washing before cooking & 986 & $49 \%$ \\
\hline Hand washing after going to the toilet & 980 & $49 \%$ \\
\hline Drinking boiled water & 971 & $48 \%$ \\
\hline Cover and protect drinking water & 632 & $32 \%$ \\
\hline Hand washing before feeding the children & 677 & $34 \%$ \\
\hline Recognition of pneumonia symptoms by mothers & & Percent \\
\hline Runny or Blocked Nose $(n=1463)$ & 512 & $35 \%$ \\
\hline Shortness of breath $(n=1677)$ & 520 & $31 \%$ \\
\hline Cough $(n=1479)$ & 414 & $28 \%$ \\
\hline Sound from the chest $(\mathrm{n}=1756)$ & 474 & $27 \%$ \\
\hline Increased respiratory rate $(\mathrm{n}=1829)$ & 256 & $14 \%$ \\
\hline Disease of lungs $(n=1379)$ & 193 & $14 \%$ \\
\hline
\end{tabular}

\section{Discussion}

We investigated the performance of LHWs for child health in an underserved area of Pakistan exploring the frequency of LHW visits to households, services covered during encounters and maternal knowledge and practices, as related to immunizations, nutrition and early management of child illness. Our findings indicate that LHWs do not regularly carry out monthly visits and the quality of monthly encounters needs improvement. While oral Polio drops administration is the most frequent service provided however other services part of the LHW key mandate such as routine immunization, nutrition, and child illness management are infrequently offered. Whereas LHWs are the main source of information to rural households for immunization, child nutrition and dealing with child illness, it has translated into less than desirable impact on knowledge and practices of mothers, highlighting missed opportunities.

Polio awareness and administration was service most frequently offered by LHWs, whereas routine immunization 
counseling, defaulter checking, and provision of vaccines was carried out in just over half of monthly encounters. LHWs were reported to be main source of routine immunization information for households, however there was high level of awareness of the mothers about Polio as compared to the other VPDs, and a fourth were unaware of any VPDs, indicating weak transfer of immunization awareness and schedules. In contrast LHWs in other countries have been far more effective in provision of routine immunization counseling and defaulter tracking. A study in India reported over $84 \%$ of mothers receiving RI counseling by CHWs (Fathima et al., 2015), a study from Uganda shows that $71 \%$ of CHWs surveyed had $\geq 95 \%$ of children under their care on track for RI (Kuule et al., 2017), while in Kenya, CHWs helped increase vaccination among infants to $98.8 \%$ (Nzioki et al., 2017).

Within the area of nutrition, growth monitoring and nutrition counseling are key LHW mandates, and are critical to control high stunting rates in Pakistan. Growth monitoring was carried out in less than $10 \%$ of household visits and growth-monitoring methods were not standardized. Furthermore, counseling on nutrition parameters was infrequently carried out with a third of encounters reporting weaning, nutritious food and breastfeeding, whereas very few instances of de-worming and development milestones counseling were recorded. Households' knowledge and practices for exclusive breastfeeding and weaning were recorded to be poor. Findings from other countries such as Nepal, Mali, and Afghanistan show much higher rates of growth monitoring as well as higher rates in correctly performing growth monitoring (Amano et al., 2014; Mayhew et al., 2014; Alvarez Morán et al., 2018). The third finding from our study relates to LHWs delivery on preparing households for early detection, management and referral of child illness, as well as hygiene counseling for mothers. Our study shows that the LHWs, rather than doctors, were reported by households to be the main source of information for initial child illness detection, with subsequent management by doctors at government and private health facilities. However, frequency and quality of LHW encounters was poor. While most mothers reported receiving ORS packets from LHWs, very few knew of appropriate usage, and only few mothers could correctly recall early signs of pneumonia. Hygiene advice for child care handling, although a mandate of LHWs, was least reported during LHW encounters with households, and mothers had poor practices of hand-washing, food covering and use of boiled water. Need for support to CHWs in management of child illnesses has been reported from other countries including studies from Peru, South Africa and Uganda (Westgard, Naraine, \& Villacorta, 2018; Stellenberg, Van Zyl, \& Eygelaar, 2015; Wanduru et al., 2016). Despite inadequate knowledge of CHWs being a frequently reported impediment (Wilford et al., 2018; Fathima et al., 2015; Guenther et al., 2017), CHWs can deliver well under controlled supervised pilot study settings (Abdel-Aziz, Mowafy, \& Galal, 2015).

Reported gaps in LHWs delivery for child health may have been due to a number of factors. We found considerable variation in the frequency of topics discussed during household visits with most emphasis on Polio. While there is high vertical accountability on Polio eradication in Pakistan led from the highest levels (Haq et al., 2019), there is fragmented and weak accountability on other preventive care aspects (Zaidi et al., 2019). It has also been argued that involvement of LHWs in frequent Polio campaigns with payment of special incentives, has detracted LHWs from providing the holistic primary healthcare to children under five (Wazir, Shaikh, \& Ahmed, 2013). Other more programmatic constraints are also reported. Poor field supervisory support to the LHWs is identified as a key programme challenge in Pakistan (Management, 2009; Rabbani et al., 2016). Increasing multitasking of LHWs (Haq, Iqbal, \& Rahman, 2008), inadequate training on communication (Ariff et al., 2010; Rabbani et al., 2016) are noted bottlenecks in the delivery of their basic mandate. Our findings are of value to the existing policy crossroads in Pakistan on deciding the direction ahead for the LHW program. We argue that instead of merely increasing the number of LHWs as laid out in the recent National Health Human Resource Vision of Pakistan attention is needed to plug missed opportunities for child care through high emphasis on improved frequency and quality of LHW encounters. We also argue that LHWs, even with existing sub-optimal delivery in child health care, are still the main source for health and nutrition awareness for rural underserved households, hence existing counter policy arguments to make LHWs redundant or not recruit against LHWs that are retiring (Shah, 2018), will not bring value for money, with a call for policy on capability development and supervision. Prioritization of a wider child health focus throughout the LHW program, to recapture its relevance beyond just polio program activities.

A limitation of the study is that LHW delivery has been indirectly assessed through mother interviews, whereas we did not carry out LHW interviews to assess whether there was insufficient knowledge of LHWs, inability to share knowledge with care-providers or lack of sufficient attention to the task. These are important areas for future research in the Pakistani context. Another limitation is that the sample of rural households was taken from the Sindh province of Pakistan rather than a national sample, however, given that the socio-economic background of mothers is fairly representative of other rural areas in Pakistan the lessons learned can be of value to other parts of Pakistan.

\section{Conclusion}


Although LHWs are main information source for child health services for households in rural underserved areas of Pakistan, but infrequent, poor quality of household encounters and weak translation into maternal knowledge and practices, indicates ineffective delivery on the key mandate of basic community-based child health services. Policy debate instead of focusing on scaling up or downsizing the program, should prioritize child health, bringing quality and supervision to improve value for money of a critical community resource.

\section{Funding}

This study was funded by Bill \& Melinda Gates Foundation under project number 51726 . The funders had no role in the design of the study and collection, analysis, and interpretation of data and in writing the manuscript.

\section{Authors' Contributions}

SZ: conceptualized, designed and supervised the study, MH led the data collection and analysis. AA provided literature review and refined the analysis: SZ, MH, AA and XG drafted the paper. All authors read and approved the final manuscript.

\section{Acknowledgments}

The authors would like to extend their gratitude to the mothers who participated in this survey. We would also like to thank the district management for their support for this study. We are grateful to Atif Riaz at Aga Khan University for contributing to the analysis. We would also like to acknowledge Midhat Fatima and Rahim S. Lalani TEXT Pvt. Ltd.

\section{Competing Interests Statement}

The authors declare that there are no competing or potential conflicts of interest.

\section{References}

Abdel-Aziz, S. B., Mowafy, M. A., \& Galal, Y. S. (2015). Assessing the Impact of a Community-Based Health and Nutrition Education on the Management of Diarrhea in an Urban District, Cairo, Egypt. Glob J Health Sci, 8, 46-55. https://doi.org/10.5539/gjhs.v8n2p46

Morán. J. L. A., Alé, G. B. F., Charle, P., Sessions, N., Doumbia, S., \& Guerrero, S. (2018). The effectiveness of treatment for Severe Acute Malnutrition (SAM) delivered by community health workers compared to a traditional facility based model. BMC Health Serv Res, 18, 207. https://doi.org/10.1186/s12913-018-2987-z

Amano. S., Shrestha, B. P., Chaube, S. S., Higuchi, M., Manandhar, D. S., Osrin, D., Costello, A., \& Saville, N. (2014). Effectiveness of female community health volunteers in the detection and management of low-birth-weight in Nepal. Rural and Remote Health, 14, 2508. PMID: 24724713

Ariff, S., Soofi,S. B., Sadiq, K., Feroze, A. B., Khan,S., Jafarey,S. N., Ali, N., \& Bhutta, Z. A. (2010). Evaluation of health workforce competence in maternal and neonatal issues in public health sector of Pakistan: an Assessment of their training needs. BMC Health Serv Res. https://doi.org/10.1186/1472-6963-10-319

Bhutta, Z. A., Ahmed, T., Black, R. E., Cousens, S., Dewey, K., Giuglianif, E., .... \& Meera, S. (2008). What Works? Interventions for Maternal and Child Undernutrition and Survival. Lancet, 371, 417-40. https://doi.org/10.1016/S0140-6736(07)61693-6

Brenner, J. L., Kabakyenga, J., Kyomuhangi, T., Wotton, K. A., Pim, C., Ntaro, M., ... \& Singhal, N. (2011). Can volunteer community health workers decrease child morbidity and mortality in southwestern Uganda? An impact evaluation. PLoS One, 6, e27997. https://doi.org/10.1371/journal.pone.0027997

Fathima, F. N., Mohan, R., Kiruba, S., Varad, H., Aditi, K., Ananthkumar, S. R., \& Prem, K. M. (2015). Assessment of accredited social health activists'-a national community health volunteer scheme in Karnataka State, India. Journal of Health, Population, and Nutrition, 33, 137-45. PMID: 25995730.

Gilmore, B., \& McAuliffe, E. (2013). Effectiveness of community health workers delivering preventive interventions for maternal and child health in low- and middle-income countries: a systematic review. BMC Public Health, 13, 847. https://doi.org/10.1186/1471-2458-13-847

Guenther, T., Salim, S., Karen, F., Erica, W., Fatima, I., Paulo, R., ... \& Amouzou, A. (2017). Contribution of community health workers to improving access to timely and appropriate case management of childhood fever in Mozambique. Journal of Global Health, 7, 010402-02. https://doi.org/10.7189/jogh.07.010402

Hafeez A., Mohamud, B. K., Shiekh, M. R., Shah, S. A., \& Jooma. R. (2011). Lady health workers programme in Pakistan: challenges, achievements and the way forward. J Pak Med Assoc, 61, 210-5. PMID: 21465929 
Haq, Z., Zafar, I., \& Atif, R. (2008). Job stress among community health workers: a multi-method study from Pakistan. International Journal of Mental Health Systems, 2, 15. https://doi.org/10.1186/1752-4458-2-15

Haq, Z., Babar, T. S., Nhan, T., Assad, H., \& Abdul, G. (2019). System within systems: challenges and opportunities for the Expanded Programme on Immunisation in Pakistan. Health Research Policy and Systems, 17, 51. https://doi.org/10.1186/s12961-019-0452-z

Horwood, C., Lisa, B., Pierre, B., Sifiso, P., Lyn, H., Merridy, G., ... Nigel, R. (2017). A continuous quality improvement intervention to improve the effectiveness of community health workers providing care to mothers and children: a cluster randomised controlled trial in South Africa. Hum Resour Health, 15, 39. https://doi.org/10.1186/s12960-017-0210-7

Iqbal, N. (2014, September 17). SC issues contempt notices in LHWs case, Dawn. Retrieved from https://www.dawn.com/news/1132479/sc-issues-contempt-notices-in-LHWs-case.

Kuule, Y., Andrew, E. D., Desalegn, W., Maria, Z., Robinah, N., Nahabwe, H., ... Ewan, W. (2017). Community Health Volunteers in Primary Healthcare in Rural Uganda: Factors Influencing Performance. Frontiers in Public Health, 5. https://doi.org/10.3389/fpubh.2017.00062

Mambulu-Chikankheni., Faith, N., John, E., \& Prudence, D. (2018). Exploring the roles and factors influencing community health workers' performance in managing and referring severe acute malnutrition cases in two subdistricts in South Africa. Health Soc Care Community, 26, 839-48. https://doi.org/10.1111/hsc.12595

Management, Oxford Policy. (2009). Lady Health Workers Program External Evaluation of the National Program for Family Planning and Primary Health Care. In. United Kingdom.

Mayhew, M., Ickx, P., Stanekzai, H., Mashal, T., \& Newbrander, W. (2014). Improving nutrition in Afghanistan through a community-based growth monitoring and promotion programme: a pre-post evaluation in five districts. Glob Public Health, 9(Suppl 1), 58-75. https://doi.org/10.1080/17441692.2014.917194

Memon, Z. A., Gul, N. K., Sajid, B. S., Imam, Y. B., \& Zulfiqar, A. B. (2015). Impact of a community-based perinatal and newborn preventive care package on perinatal and neonatal mortality in a remote mountainous district in Northern Pakistan. BMC Pregnancy Childbirth, 15, 106. https://doi.org/10.1186/s12884-015-0538-8

National Institute of Population Studies (NIPS), ICF. (2019). Pakistan Demographic and Health Survey, 2017-18.

National Institute of Population Studies (NIPS), ICF International. (2013). Pakistan Demographic and Health Survey, 2012-13. In. Islamabad; Pakistan, Calverton; Maryland, USA.

Nina, Z., Elizabeth, A., Annie, K., Jacquelyn, C., \& Rifat, A. (2014). Lady Health Workers in Pakistan: Improving access to health care for rural women and families.

Nzioki, J. M., James O., James, H. O., \& Rosebella, O. O. (2017). Community health worker interventions are key to optimal infant immunization coverage, evidence from a pretest-posttest experiment in Mwingi, Kenya. The Pan African Medical Journal, 28, 21-21. https://doi.org/10.11604/pamj.2017.28.21.11255

Rabbani, F., Leah, S., Wafa, A., Kashif, S., Shagufta, P., \& Aysha, Z. (2016). Inspiring health worker motivation with supportive supervision: a survey of lady health supervisor motivating factors in rural Pakistan. BMC Health Serv Res, 16, 397. https://doi.org/10.1186/s12913-016-1641-x

Report, Dawn. (2018, March 31). LHWs end sit-in after service structure notification. Retrieved from https://www.dawn.com/news/1398611.

Shah, Rukhsana. (2018, September 16). Supporting LHWs, Dawn. Retrieved from https://www.dawn.com/news/1433208.

Sindh Bureau of Statistics, UNICEF. (2015). Sindh Multiple Indicator Cluster Survey 2014, Final Report. In. Karachi, Pakistan.

Statistics, Pakistan Bureau of. (2018). Block Wise Provisional Summary Results of 6th Population \& Housing Census-2017. Retrieved from http://www.pbs.gov.pk/content/block-wise-provisional-summary-results-6thpopulation-housing-census-2017- january-03-2018.

Stellenberg, E., Marjorie, V. Z., \& Johanna, E. (2015). Knowledge of community care workers about key family practices in a rural community in South Africa. Afr $J$ Prim Health Care Fam Med, 7, 1-7. https://doi.org/10.4102/phcfm.v7i1.892

Uganda, Healthy Child. (2011). Community Health Workers and Community Case Management: Policies and 
Progress in Uganda within a Global Context, Review of the Literature and Situational Analysis. Retrieved from https://www.healthychilduganda.org/media/Community-Health-Workers-and-Community-CaseManagement-April-2011.pdf

Walker, C. L. F., Rudan, I., Liu, L., Nair, H., Theodoratou, E., Bhutta, Z. A., ... \& Black, R. E. (2013). Global burden of childhood pneumonia and diarrhoea. Lancet, 381, 1405-16. https://doi.org/10.1016/S0140-6736(13)60222-6

Wanduru, P., Tetui, M., Tuhebwe, D., Ediau, M., Okuga, M., Nalwadda, C., ... \& Rutebemberwa, E. (2016). The performance of community health workers in the management of multiple childhood infectious diseases in Lira, northern Uganda - a mixed methods cross-sectional study. Glob Health Action, 9, 33194. https://doi.org/10.3402/gha.v9.33194

Wazir, M. S., Babar, T. S., \& Ashfaq, A. (2013). National program for family planning and primary health care Pakistan: a SWOT analysis. Reprod Health, 10, 60-60. https://doi.org/10.1186/1742-4755-10-60

Westgard, C., Renuka, N., \& Diego, M., \& Paucar, V. (2018). Performance evaluation of community health workers: case study in the Amazon of Peru. $J$ Community Health, 43, 908-19. https://doi.org/10.1007/s10900-018-0503-3

Wilford, A., Phakathi, S., Haskins, L., Jama, N. A., Mntambo, N., \& Horwood, C. (2018). Exploring the care provided to mothers and children by community health workers in South Africa: missed opportunities to provide comprehensive care. BMC Public Health, 18, 171. https://doi.org/10.1186/s12889-018-5056-y

Zaidi, S. A., Maryam, B., Etienne, V., Langlois, A. R., David, W. O., Nasir, I., \& Jesse, B. B. (2019). Health systems changes after decentralisation: progress, challenges and dynamics in Pakistan. BMJ Global Health, 4 , e001013. https://doi.org/10.1136/bmjgh-2018-001013

\section{Copyrights}

Copyright for this article is retained by the author(s), with first publication rights granted to the journal.

This is an open-access article distributed under the terms and conditions of the Creative Commons Attribution license (http://creativecommons.org/licenses/by/4.0/). 